\title{
Spatial Analysis Flood Risk Exposure in Ajeokuta Using Geographic Information System (GIS)
}

\author{
Ahuchaogu Udo. E, Njoku R. E, Baywood C.N \\ Department Of Surveying And Geo-Informatics Federal University Of Technology Owerr
}

\begin{abstract}
Heavy floods in Nigeria have shown increasing trend in recent years. Ajeokuta is one of the areas affected annually by flood due to its location along the river Niger basin. Flood risk mapping and analysis are vital elements for appropriate land use planning in flood prone areas. The aim of this paper is to demarcate flood risk potential areas and determine the spatial impact of the recent major flood event in Ajeokuta using Remote Sensing and GIS techniques. Identified flood inducing factors in the study area, such as slope, elevation, drainage density, proximity to the river and land use were reclassified and combined to delineate flood risk zones using multi-criteria approach in a GIS environment. The idea was to identify the areas with the highest number of flood inducing factors and assess its proximity to the inundated areas during the recent flood events as a criteria for determination of locations for future flood events. Moderate resolution imaging spectroradiometre (MODIS) data of NASA terra satellite, SRTM, Landsat image with resolution of $30 \mathrm{~m}$, geographical map of the study area and geographical information system (GIS) were used for this purpose. Each of the flood indicators was reclassified into four which included high risk, moderately risk, low risk, and no risk through ranking process. Flood risk map (FRM) was later generated by overlaying the reclassified maps of all the parameters using addition operator and validated with a view to assisting decision makers on the menace posed by the disaster. The flood risk map revealed that the very high risky places covered area of 376.31 square kilometers $(27.63 \%)$ while high risky covered 322.88 square kilometers $(23.71 \%)$, The low risky areas covered 151.76 square kilometers $(11.14 \%)$ and areas free from risk covers 511.040 square kilometers $(37.52 \%)$. This analysis further revealed that 56 settlements are within the very high risk zone these includes Geregu, Gbokojo, Adogu, upake, Adogo, Achaga, Badogo, upaga etc
\end{abstract}

Keywords: Risk, Flood Disasters, GIS, S.R.T.M, MODIS

DOI: $10.7176 / \mathrm{JEES} / 10-8-07$

Publication date:August $31^{\text {st }} 2020$

\subsection{Introduction}

Flooding is one of the major causes of natural disaster and has frequently resulted to loss of lives and property. In recent times there have been extreme climatic conditions due to climate change. As a result of this, the intensity of rainfall has increased tremendously causing floods in many areas and countries worldwide (Emmanuel et all 2017). Floods can be explained as excess flows exceeding the carrying capacity of river channel, lakes, ponds, reservoirs, drainage system, dam and any other water bodies, whereby water inundates outside water body areas (Getahun YS and Gebre SL 2015). Flooding is also defined as a large amount of water covering an area that was usually dry (Olajuyigbe et al., 2012). Nwafor (2006) defined flood as a natural hazard like drought and desertification which occurs as an extreme hydrological (run off) event. Flooding can be caused by factors such as, heavy rain, snow melt, land subsidence, rising of groundwater, dam failures, Rise of sea level etc. International Federation of Red Cross and Red Crescent Societies noted that in 10 years from 1993 to 2002 flood disasters affected more people across the globe (140 million per year on average) than all the other natural or technological disasters put together (IFRC, 2001). The immediate effects of flood are displacement of people and damage of properties. Apart from the threat to disease, also farm land and agricultural products will be destroyed which often leads or result to poverty, hunger and starvation in addition to the cost of reconstruction and reclaiming the affected areas (Emmanuel et al 2017). Although flood hazard is natural but human modification and alteration of natural right of way can accentuate the problem while the disastrous consequences are dependent on human activities and occupancy in the flood hazard areas. In the past, decades in Nigeria, thousands of lives and properties worth millions of naira have been lost by flooding every year. In 2012 the destruction caused by flooding in Nigeria was beyond imagination. One way to mitigate the effect of flooding is to ensure that all vulnerable areas are identified. The inundation or risk assessment mapping delineates flood risk areas in the river basin by integrating identified flood inducing factors. The inundation or risk mapping is an essential component of emergency action plans it supports policy and decision makers to decide about how to allocate resources for flood mitigation. It creates charts and maps that can facilitate administrators and planners to identify areas at risk and prioritize their mitigation and response effort. Fig1.1 are situations created by past flood events in the study area 


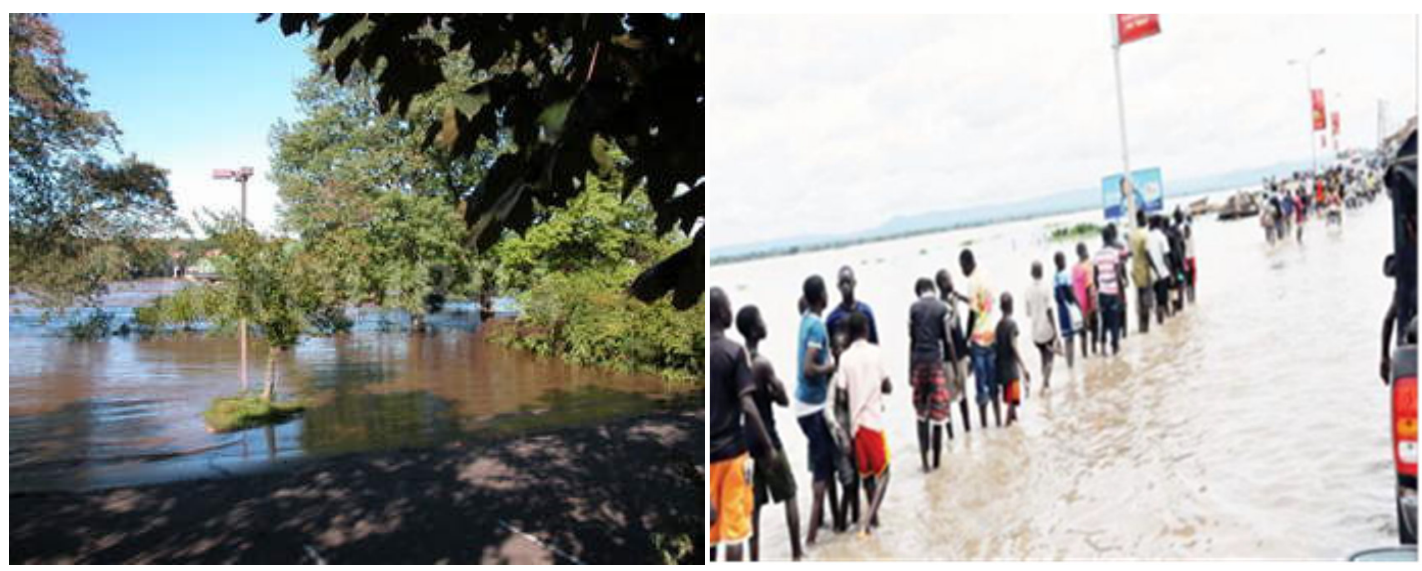

Fig 1.1 situations during past flood events in the study are

\subsection{Aim and Objectives}

The aim of this study is to assess the spatial extent of the recent major flood event and determine flood risk potential areas in Ajeokuta

\section{Objectives}

$>$ To Understand the general topography, of the study area.

$>$ To prepare flood map of the study area

$>$ To Prepare a flood risk map of the study area,

$>$ To Assess the relationship between the risk map and the inundation map

$>$ To suggest strategies for future flood disaster and risk mitigation in the study area

\subsection{Study Area}

Ajaokuta is a Local Government in Kogi State, Nigeria and a town on the left bank of Niger River. Ajaokuta Local Government was created from Okene Local Government Area on 27th August 1991 and has its headquarters at Adogo. It is bounded to the North west by Lokoja LGA, Bassa Local Government to the North East, Ofu Local Government to the East and South-West by Okene and Adavi Local Government Areas respectively. The major occupation of the people is the production of cash and food crops as well as fishing. The vegetation of the area further provides positive environment to the major occupation of the people especially Sahel Savannah which favors trees like locust beans, palm trees, iroko, mahogany etc. It has a landmass of $\mathbf{1 , 3 6 2} \mathbf{~ k m}^{2}$ and a population of 122,321 at the 2006 census. Geographically it is located at latitude $7^{\circ} 33^{\prime} 22^{\prime \prime} \mathrm{N}$ and $6^{\circ} 39^{\prime} 18^{\prime \prime} \mathrm{E}$. 


\section{Location Map of the Study Area}

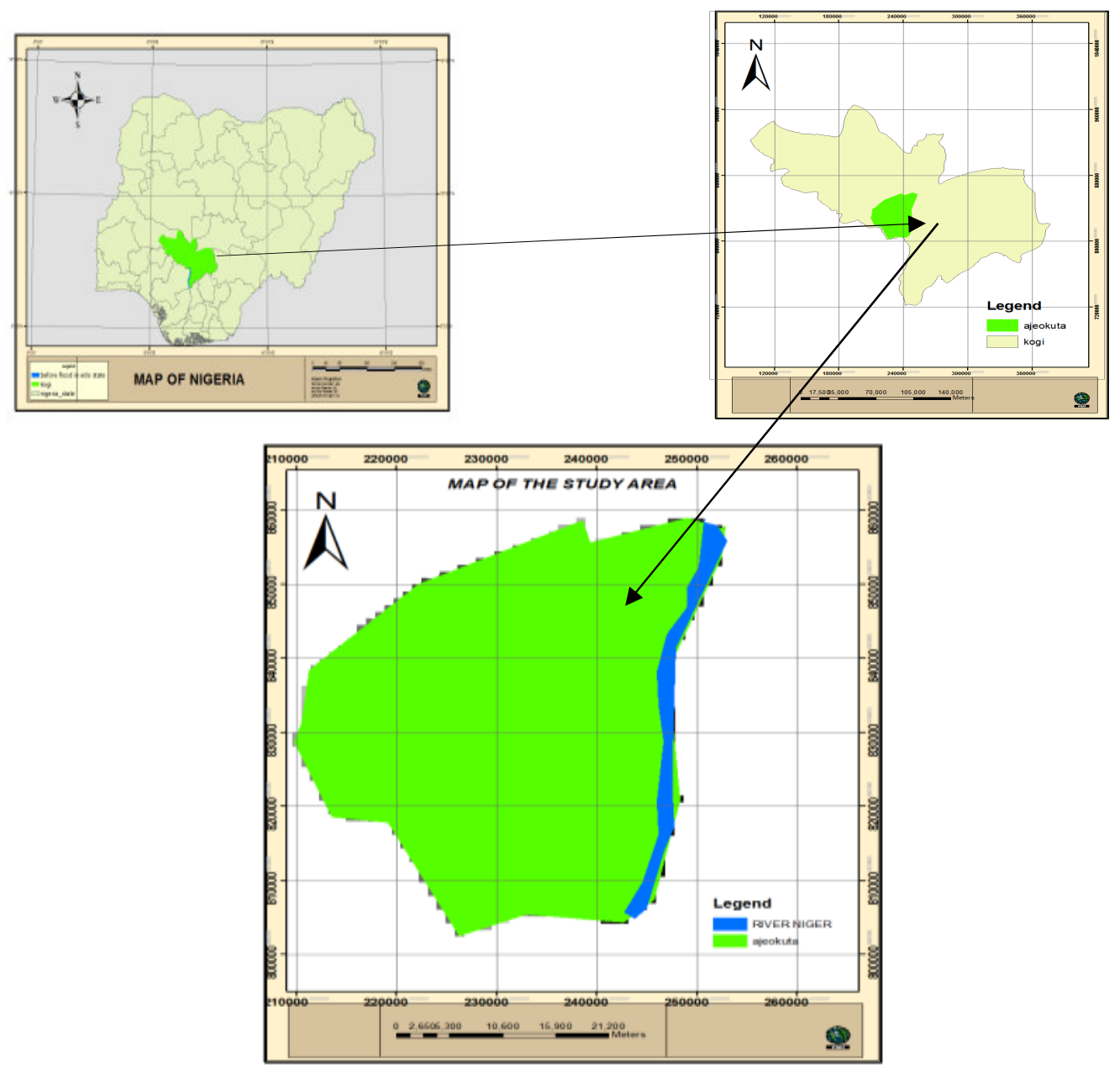

FIG 1.2 Location Map

\subsection{Materials and Methods}

The data used for this study includes the Shuttle Radar Topographical Mission (SRTM) data with resolution of 3 arc seconds. This was used for generation of contour map, 3-D models, Digital Elevation Model, drainages and flow direction map. Other datasets includes prior and during 2012 flood remote sensing satellite imageries captured by moderate resolution imaging spectroradiometer (MODIS) on NASAS terra satellite, Landsat image with resolution of $30 \mathrm{~m}$ obtained from Global land cover facility and administrative map of the study area. Other materials include hand held GPS and laptop. Software includes ArcGIS 10.1, ERDAS and Sufer11.

\subsection{Flood Extent Mapping}

The time series flood imageries and the administrative map were geo-referenced to WGS84 ZONE 32 in Arc-GIS 10.1 , using common reference points. The reason for identifying in the same coordinate system is to ensure compatibility between the various environmental data-set. The creation of a personal geodatabase for each feature of interest was done in ArcCatalog extension of the ArcGIS 10.1. The digitizing process was done in the ArcMap environment for feature extraction. The true width of the river channel was extracted from pre-disaster imagery as polygons (shape file) and in the same process, the flood mask along the river channel from the disaster image was digitized as polygons. The map generated from the non-flood image captured on $20^{\text {th }}$ October 2010 was used as a reference to determine the extent of innundation

\subsection{Overlay Analysis}

For detail study, the Niger River layer and the flood mask layer were both overlaid on the administrative map (Figure 3.1a). Spatial erase was carried out on the new map to erase the river feature that falls within the area of the flood polygon this also removed the true width of the Niger River from the area affected by flood. This procedure was able to separate the flooded area from the actual river channel so as to reveal the spatial extent of the flood. With the application of GIS spatial analysis, water covered area was synthesized. After spatial erasing 
of the true river channel (blue), the flooded area marked by red color was mapped out. A ground truthing was also conducted to validate the extent of the flood as captured by the satellite imagery and to identify other flooded areas. This study analysis revealed that 167.94square kilometers of land along the basin excluding the original extent of river Niger was affected and this constitute $12.33 \%$ of the land mass of the study area

\subsection{Terrain analysis}

The SRTM tiles were added to ArcGIS window for processing. The tiles of the elevation raster were mosaicked using data management module of Arc-tool box in ArcGIS 10.1. The mosaicked data was transformed from geographic coordinate system to projected coordinate system (i.e. from GCS-WGS1984 to WGS1984 World Mercator and masked with the boundary shapefile of the study area for proper boundary delineation. The resultant data was used to generate the slope map and flow accumulation map. For the purpose of further analysis, the mosaicked data was converted to XYZ point data and exported to surfer10 worksheet where the data was resampled to a grid interval of $40 \mathrm{~m}$. The resample data was blanked from the blanked file, elevation model contour, $3-\mathrm{D}$, and flow vectors, of the study area were generated. These models shows terrain elevation range of between $20 \mathrm{~m}$ to $360 \mathrm{~m}$ above mean sea level with elevation decreasing towards the river Niger.

\subsection{Risk map base on elevation and slopes}

Elevation is considered to be the most important factor in determination of the direction of flowing water because water flows by gravity. This study considered the fact that areas of lower elevation are prone to flood than high elevated areas. Therefore based on elevation risk Map was generated by re-classifying the elevation data into four categories (figure3.3a) Elevation range of (20m - 100), (101-160), (161-220) (221-360) was classified as high risk, moderate risk, low risk, and no risk and these was validated with areas that flooded from historical records. Base on slopes, risk map was also generated taking into consideration categories of surface slope degrees identified within the study area, (figure3.3b)

\subsection{Risk map based Drainage density.}

Water channels take several geometric patterns, and compose of a collection of natural networks. However, the most important in drainage distributions is the density of tributaries among the basin. For example, we can find areas with high drainage density faced with areas with a lower drainage density. Drainage density is measured by dividing the total length of the river in a basin by the area of the basin. Studies have proved that areas with higher drainage densities are prone to flood more than areas of lower drainage density. The elevation raster was used to delineate the drainage network of the study area which was later vectorised and the largest river (River Niger ) was extracted from the Landsat imagery. The drainage network was overlayed on the catchment map as a basis of determination of the drainage densities of the river basins within the study area. Based on the values of the drainage densities, risk map was produced. (figure3.3c)

\subsection{Risk map based on Land Use /Land Cover}

The land use /land cover map of the study area was produced based on un-supervised classification carried on the Landsat imagery using ERDAS software. The land use categories were vectorised as layers using ArcGIS 10.1. This analysis revealed that there are five land use/land cover types within Ajeokuta. These are Farmland lands, water bodies, Swamps, built up areas, and forest. The risk map was produced based on the ability of each land use to infiltrate water. Water bodies and swamps was classified as high risk. Built up areas consist of impermeable surfaces that resists infiltration and was classified as moderate risk, farm lands was classified as low risk while forest areas was classified as no risk.

\subsection{Risk map based on proximity to the river}

This study, based on the fact that river flooding is directly related to nearness to drainage as a yard-stick for risk classification. The vectorised river (River Niger ) was buffered. 2kilometre buffer distance was chosen on both side of the river channel (which is equivalent to $4 \mathrm{~km}$ across) representing low risk. Progressively, 1-kilometre and 1.5-kilometre buffer distances on both side (equivalent to $2 \mathrm{~km}$ and $3 \mathrm{~km}$ across respectively) were identified within the 4-kilo- meter buffer representing high risk and moderate risk. The 2-kilometre and 1-kilometre buffer distances were derived from the maximum and minimum width respectively of the flooded area detected from historical flood event within the study area. The 1.5-kilometre buffer distance is derived from the mid-point (average) between the maximum and minimum buffer distances while the 3kilometer representing no risk buffer was added to give room for unforeseen circumstance i.e. if flood exceed the previous maximum which areas will be affected. In the same format, the smaller drainages were buffered at a distance of $100 \mathrm{~m}, 150 \mathrm{~m}, 200 \mathrm{~m}$ and $300 \mathrm{~m}$ representing high risk, Moderate risk. Low risk and no risk respectively. 


\subsection{Risk mapping of kogi state:}

This study employed Analytical Hierarchical Process (AHP) to carry out the risk assessment. AHP is a multicriteria decision making technique, which provides a systematic approach for assessing and integrating the impacts of various factors, involving several levels of dependent or independent, qualitative as well as quantitative information (Bapalu and Sinha, 2006) In this study, the risk areas were first produced based on several factors which includes proximity to drainage network, slope degrees, land use /land cover, drainage density and elevation. The selection of these criteria was based on the expert's opinion and availability of data. To generate the final risk map, each of the parameters was reclassified into four which included high risk moderate risk, low risk and no risk based on estimated significance of causing flood. Final Flood risk map (FRM) was later generated by overlaying the reclassified maps of all the parameters using addition operator and the categories of risk was based on number of flood inducing factor identified within each zone and number of communities located within the region. Finally, the map generated was validated using the risk map

\subsection{Results And Discussions}

\subsection{Results}

Figure 3.1a is the 2012 flood map of the study area Fig 3.2a is the contour map of the study area. fig3.2b is the overlay analysis of contour and DTM of the study area. Fig3.2c is the 3-D model of the study area Fig 3.3a, is the flood risk of the study area based on elevation. Figure3.3b is the flood risk of the study area based on slope. Figure3.3c is the flood risk of the study area based on drainage density. Fig 3.3d is the flood risk of the study area based on land use fig3.3e is the risk map based on proximity to the river and Fig 3.4 is the risk map generated by integrating the flood inducing factors, While (figures 3.5 and b) are the charts revealing the area of land occupied by the risk zones, and percentages of land occupied by the risk categories.

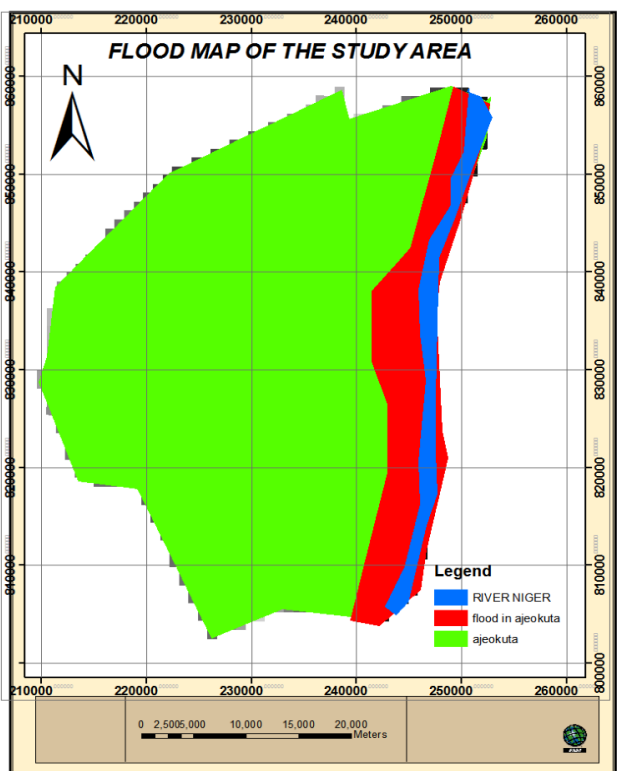

Fig 3.1a f 2012 flood map of the study area

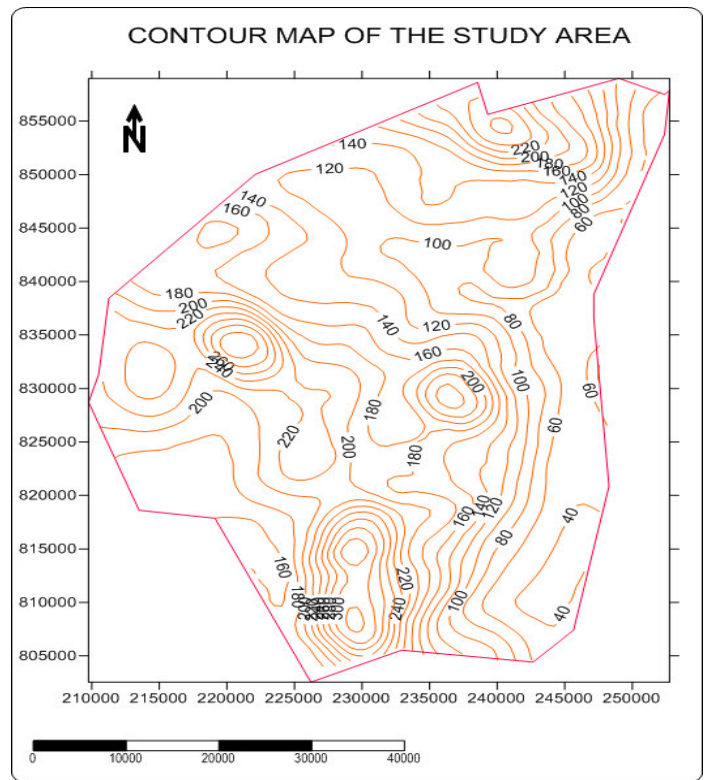

Fig 3.2a contour map of the study area 

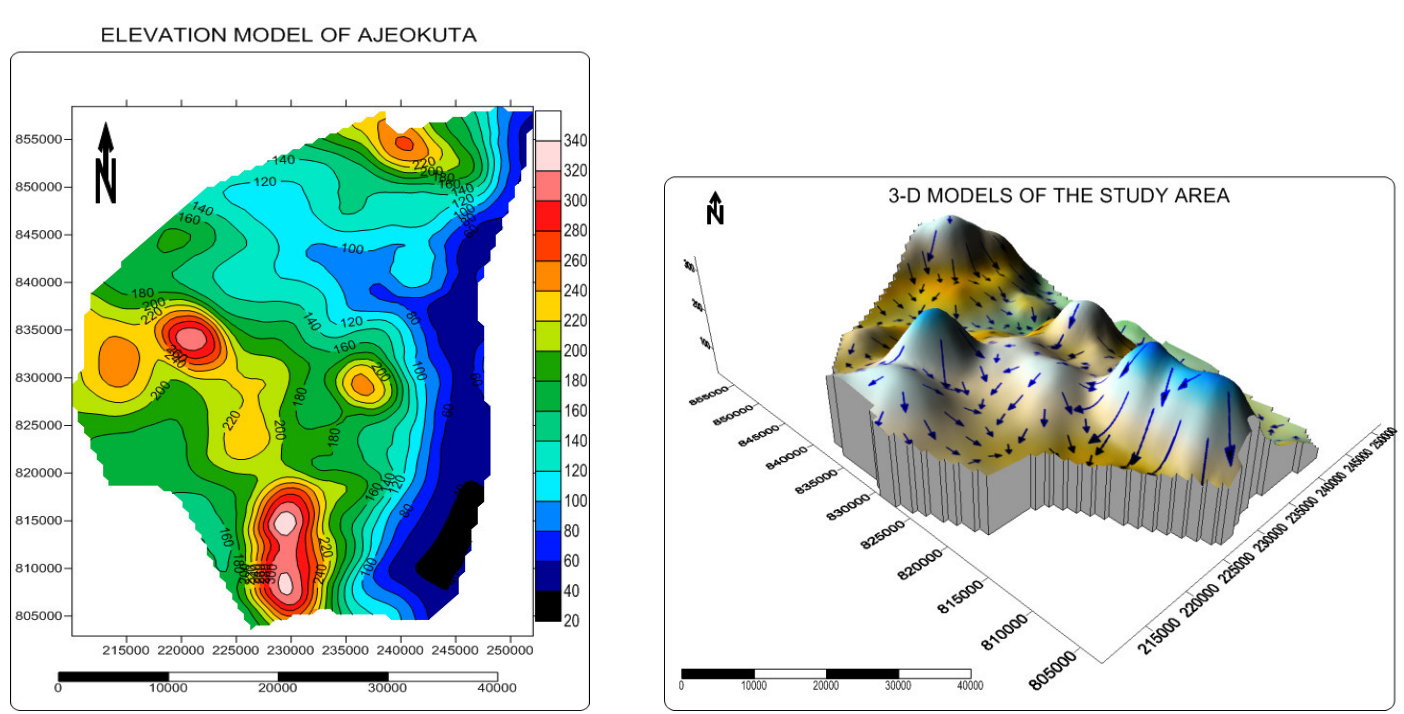

Fig 3.2b DTM the study area

Fig 3.2c Overlay analysis of flow and 3-D models

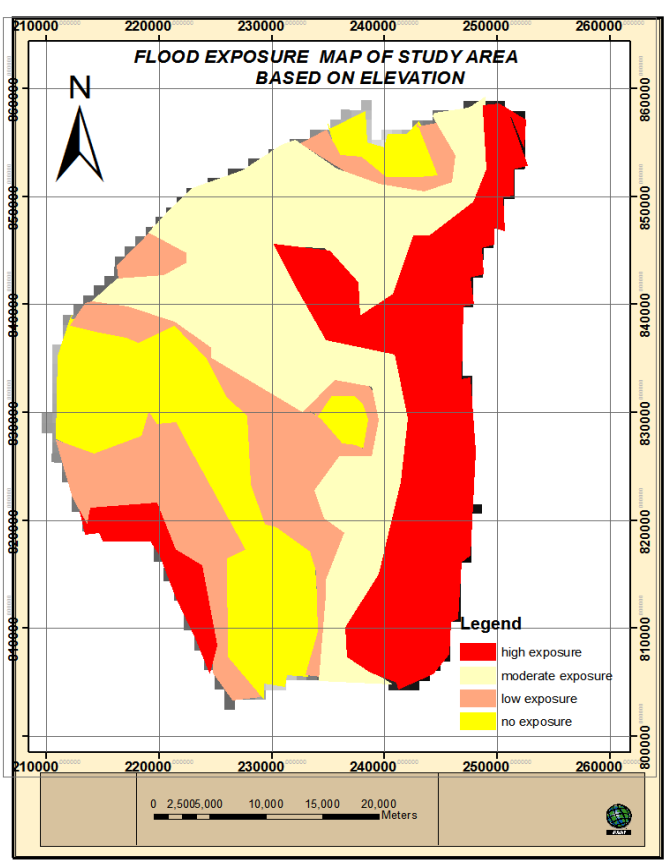

Fig 3.3a Flood risk base on elevation

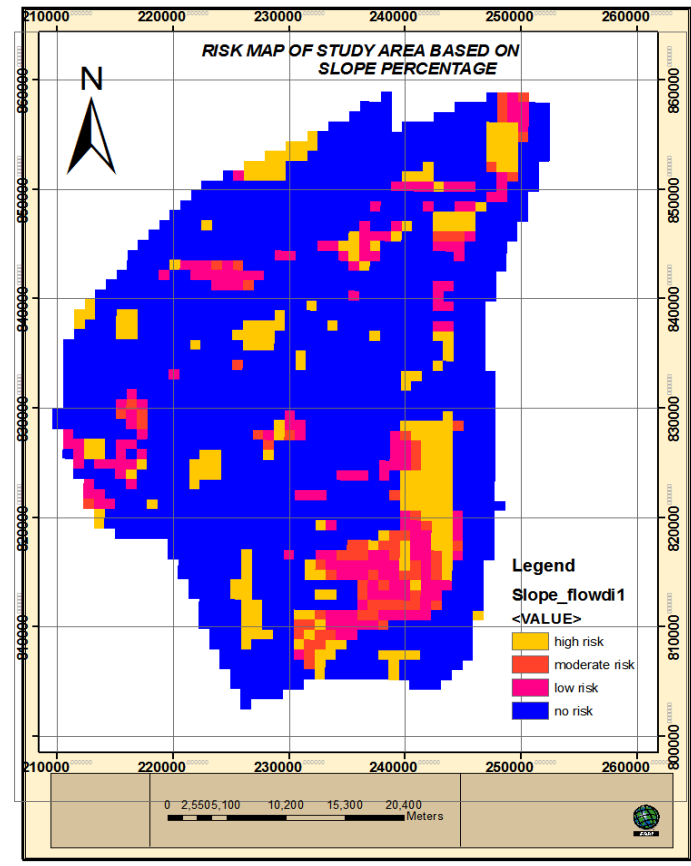

Fig 3.3b flood risk based on slope degree 


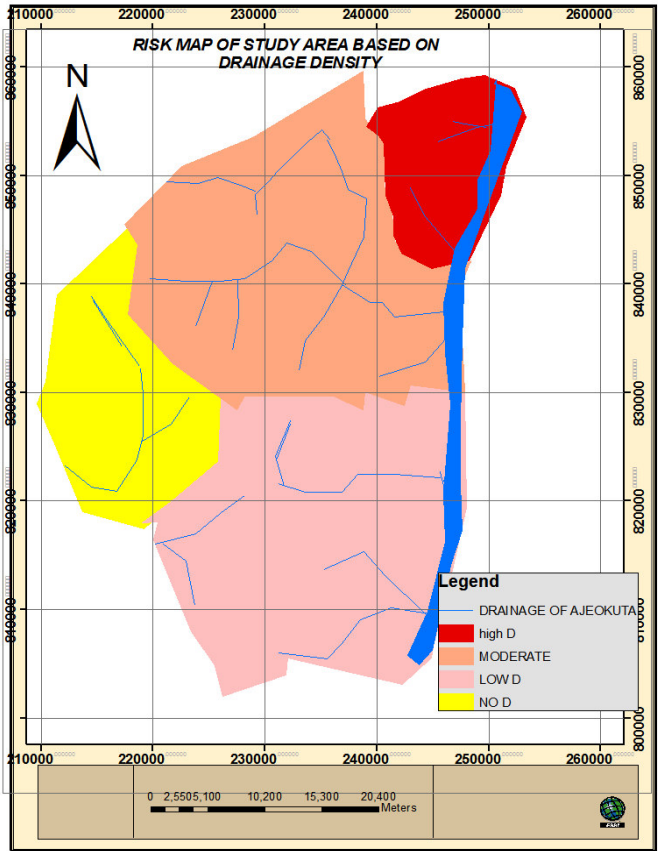

Fig 3.3c Flood risk drainage density

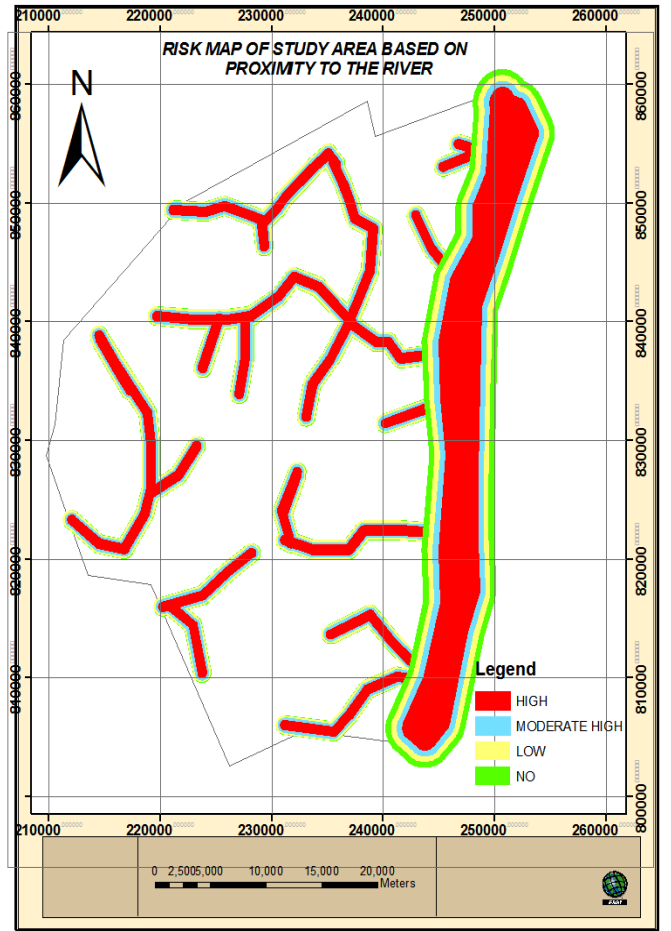

3.3e flood risk based on proximity to drainage

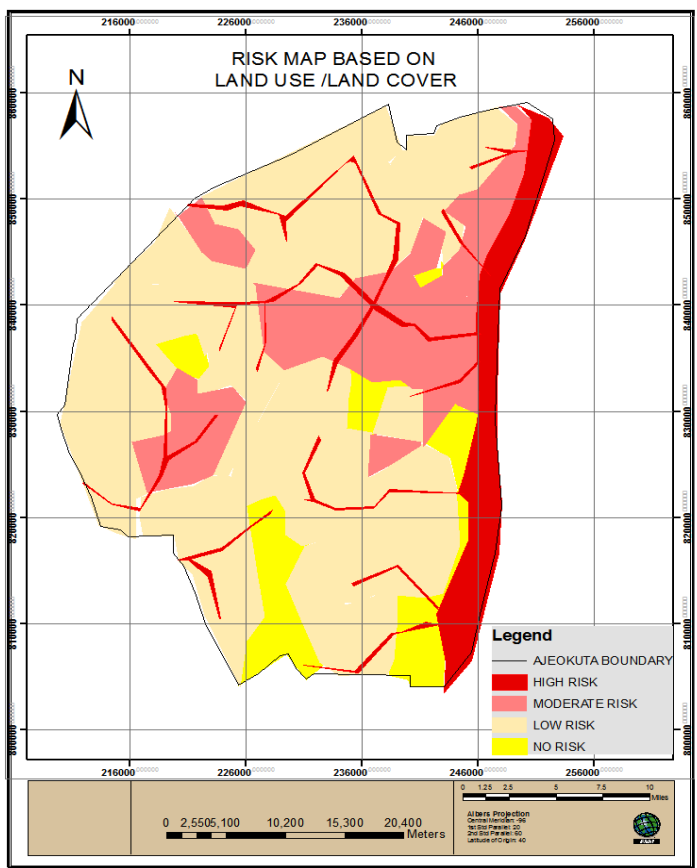

Fig 3.3d flood risk based on Land use

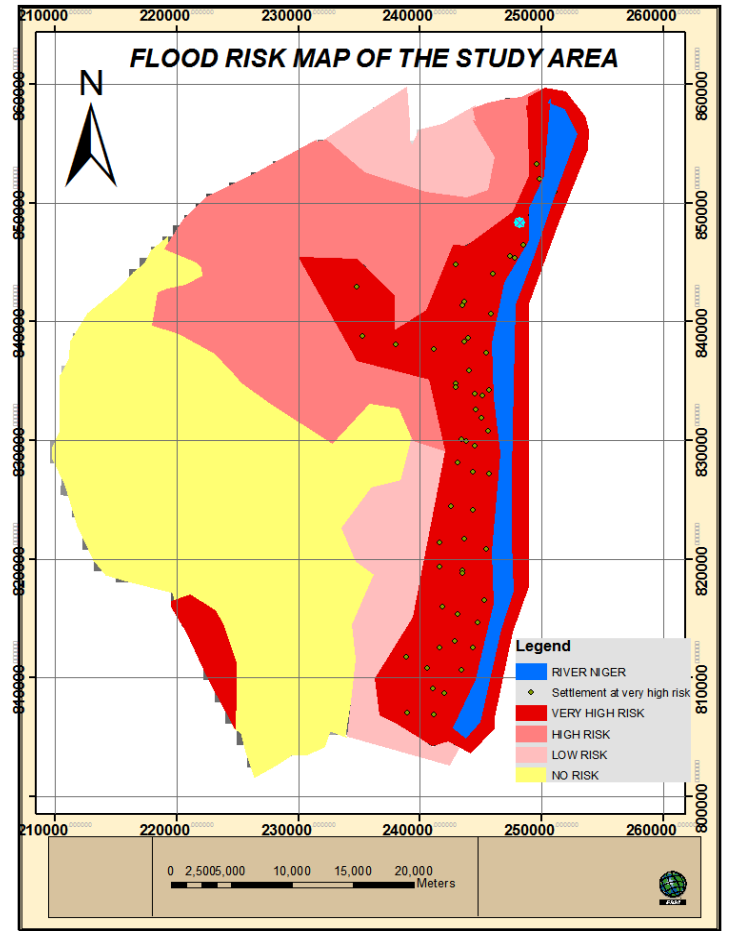

Fig 3.4 flood risk map of he study area 


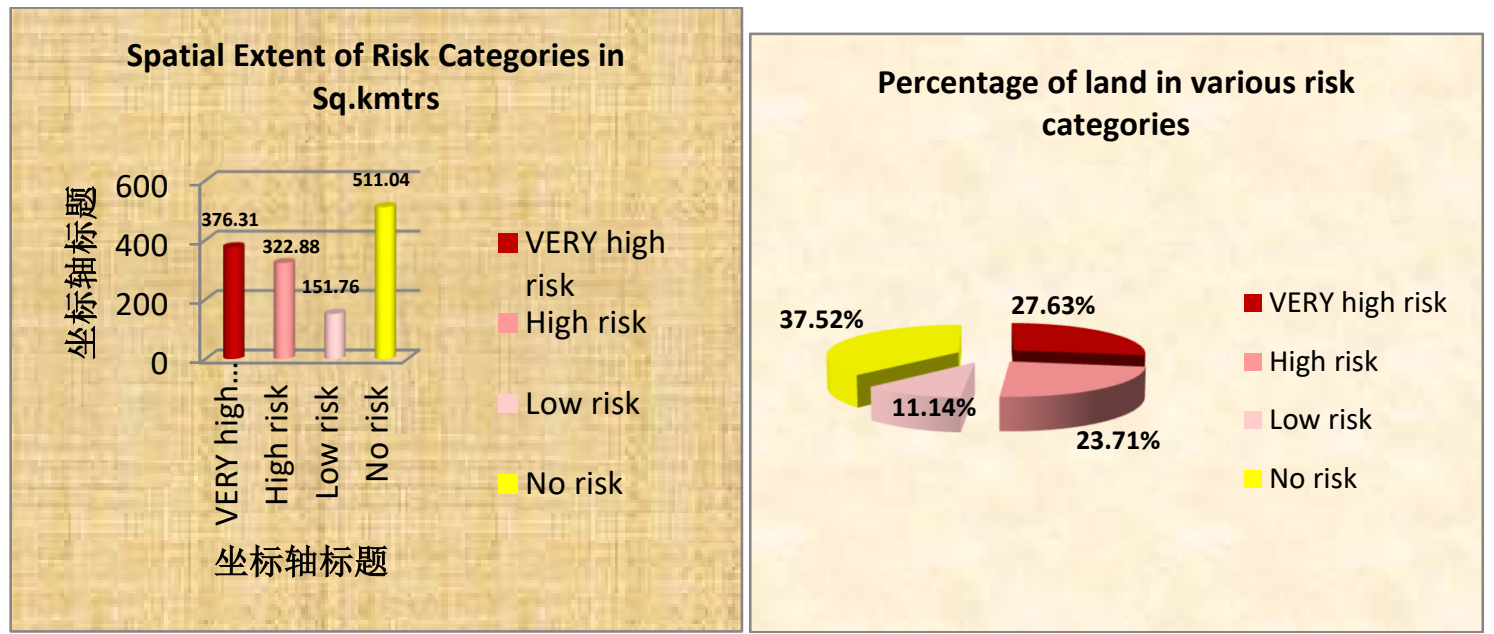

Fig 3.5a Area of land occupied by risk categories Fig 3.5b Percentage of land occupied by risk categories

\subsection{Discussion of Result}

The surface analysis revealed that the study area is undulating and situated within locations of elevation range of between $20 \mathrm{~m}$ to 360 above mean sea level with elevation decreasing towards the river Niger. Quantitatively,the flood risk map revealed that the very high risky places covered area of 376.31 square kilometers (27.63\%) while high risky covered 322.88 square kilometers (23.71\%), The low risky areas covered 151.76 square kilometers $(11.14 \%)$ and areas free from risk covers 511.040 square kilometers (37.52\%). Comparison of the flood risk map and flood map revealed that the inundated areas are situated within zones classified at very high risk. This analysis further revealed that 56 settlements are within the very high risk zone and these includes Geregu, Gbokojo, Adogu, upake, Adogo, Achaga, Badogo, upaga communities etc

\subsection{Recommendations}

In response to the re-occurring flood events in Ajeokuta and in Nigeria as a whole,

(1) There is the need to intensify environmental education

(2) There should be continual risk mapping of cities in Nigeria.

(3) There is the need to improved land Use Planning in the study area.

(4) Flood monitoring and management should be encouraged and funded by government and non- governmental agencies.

\section{Refferences}

Barroca, L., 2006. Indicators for Identification of Urban Flooding Vulnerability. National Hazards Earth System, Science. 6: $553-561$.

Emmanuel udo 2017, Flood River Inundation and Flood Hazard Zonation in Edo State Using Sensing Approach, The International Journal of Engineering and Science 2017, 6(8): 48-59

Felix Ndidi Nkeki (2013). Geospatial Techniques for the Assessment and Analysis of Flood Risk along the NigerBenue Basin in Nigeria, Journal of Geographic Information System http://dx.doi.org/10.4236/jgis.2013.

Getahun Y.S and Gebre S.L (2015) Flood Hazard Assessment and Mapping of Flood Inundation Area of the Awash River Basin in Ethiopia using GIS and HEC-georas/HEC-RAS Model. Journal Civil andEnviron Engineering , 5(4.) pp1-12

Nwafor A.N (2006), Flood Extent Mapping In Bayesa State, Naigeria. Journal of Geography, Vol. 8 (33), pp 182

Olajuyigbe, E A, (2012) Mapping And Analysis Of 2012 Flood Disaster In Edo State Using Geospatial Technic. Journal Of Environmental sciences, vol. 6 (5), PP 32-44.

Ologunorisa, E. T. (2004). An Assessment of Flood Vulnerability Zones in the Niger Delta, Nigeria. International Journal of Environmental Studies, Vol. 61(1), pp. 31-38.

Ologunorisa, T. E. (2009) ,„,Strategies for Mitigation of Flood Risk in the Niger Delta, Nigeria ${ }^{\text {eeee }}$. Journal ofl Appl. Science and Environ. Manage. Vol. 13(2) 17- 22

Sunday Ishaya 2009. mapping flood vulnerable areas in a developing urban centre of Nigeria Journal of Sustainable Development in Africa (Volume 11, No.4, 2009. 